\title{
In vitro Regeneration of the Medicinal Herb of Nilgiri shola, Acmella calva L. from Leaf Derived Callus
}

\author{
P. Senthilkumar, S. Paulsamy*, K. K. Vijayakumar \\ and K. Kalimuthu ${ }^{1}$ \\ Department of Botany, Kongunadu Arts and Science College, Coimbatore-641 029, India
}

Key words: Acmella calva, Leaf derived callus, Nilgiris, India

\begin{abstract}
Callus culture was initiated from leaf discs on MS supplemented with BAP, NAA and $\mathrm{Kn}$. The highest frequency (95\%) of organogenic callus induction was observed in MS containing BAP at $3.0 \mathrm{mg} / 1$ and NAA at $0.3 \mathrm{mg} / 1$. Development of adventitious shoots occurred when the calli were subcultured on MS supplemented with BAP alone at the rate of $3.0 \mathrm{mg} / 1(80 \%)$ and BAP with NAA at the rate of 3.0 and $0.3 \mathrm{mg} / \mathrm{l}$, respectively $(95 \%)$ and BAP with $\mathrm{Kn}$ at the rate of 3.0 and $0.3 \mathrm{mg} / \mathrm{l}$, respectively $(70 \%)$. The root initiation and the rate of growth were higher in the basal medium containing BAP at 3.0 and $2.5 \mathrm{mg} / \mathrm{l}$. The plantlets were establish successfully in the hardening medium composed by coir pith and soil $(1: 1)$.
\end{abstract}

\section{Introduction}

The plant species, Acmella calva L. (Family: Asteraceae) is commonly known as toothache plant. It is a rich source of therapeutic elements and is also reported to have medicinal as well as pesticidal properties. It is mainly found in the shola understories of the high hills of Nilgiris, the Western Ghats, India. It is an erect annual herb attaining a height of $50-60 \mathrm{~cm}$ and it has yellow cone-like flowers. As per traditional knowledge in Assam, chewing the flowers can provide a person relief from toothache (Purabi and Kalita 2005). In Western India, the flowers are used as a remedy for stammering children (Ansari et al. 1988). The plant is highly toxic to adult houseflies, Anopheline and Culicine larvae. The hexane extract of dried flower buds of Acmella calva contains bioactive Nisobutylamides, which are effective against the housefly, Aedes aegypti larvae (Ramsewak et al. 1999). The plant has marked larvicidal potential against the Culex quinquefasciatus (Pitasawat et al. 1998). The roots, flower heads and the whole aerial part yield a compound known as spilanthol, which is a powerful stimulant, sialogogue and local anesthetic. Due to these medicinal values, the

*Corresponding author. E-mail: paulsami@yahoo.com 1Department of Biotechnology, Hindusthan College of Arts \& Science, Coimbatore-641 028, India. 
plant is being over-exploited in recent years in Nilgiris (Paulsamy 2005). In addition, the efficiency of reproduction is also found to be less (Paulsamy 2006). Hence, in the present study, a standard protocol was developed through in vitro culture by using leaf explant to improve the population density of the species in their habitats.

\section{Materials and Methods}

Leaf segments from the young and healthy branches of Acmella calva were used as explants. Since the explants collected from the natural habitats failed to produce callus due to the presence of internal fungus, the leaves were collected from the pot cultured individuals through cuttings which were maintained in a mist chamber. The collected immature leaves were washed with tap water twice and then treated with $5 \%$ tween- 20 solution for $5 \mathrm{~min}$ for surface sterilization and rinsed with tap water. To eliminate the fungal contamination, explants were treated with carbendazim (50\% w/v) fungicide (10\%) also for $15 \mathrm{~min}$ and rinsed with tap water. To eliminate bacterial contamination explants were also treated with 5\% antibiotics (Ampicillin and Rifampicin) for $30 \mathrm{~min}$ followed by 3 rinses in sterile double distilled water. Furthermore, surface sterilization was carried out by dipping the explants in a $0.1 \% \mathrm{HgCl}_{2}$ for $3 \mathrm{~min}$ followed by three - four rinses in sterilized double distilled water. MS basal medium containing 3\% sucrose solidified with $1 \%$ agar (tissue culture grade, Himedia, India) was used. The $\mathrm{pH}$ of the medium was adjusted to $5.6-5.8$ prior to the addition of agar. The explants were transferred to culture bottles containing $25 \mathrm{ml}$ MS basal medium supplemented with different concentrations of BAP, NAA and $\mathrm{Kn}$ for callus induction. Cultures were incubated at $25 \pm 2^{\circ} \mathrm{C}$ under $16 \mathrm{~h}$ photoperiod from cool white fluorescent tubes giving 2000 lux at culture level. Callus from these primary cultures were transferred to MS containing different concentrations of BAP, NAA and Kn and incubated in light for shoot differentiation. Shoot buds that originated from leaf callus after 30 days were subcultured. Data on shoot proliferation efficiency were recorded after 12 weeks of culture. Proliferated shoots were transferred to MS with different concentrations of BAP, NAA and $\mathrm{Kn}$ for adventitious root formation. For hardening, pot culture experiment was conducted by using a mixture of coir pith and soil $(1: 1)$ and survivability rates were determined after 40 days of hardening. Five replicates were maintained for the culturing experiment of callus formation and subculturing experiments of shoot and root formation. For hardening experiments triplicate samples were maintained. 


\section{Results and Discussion}

Callus induction was observed on MS containing different concentrations and combinations of BAP, NAA and Kn within 15 - 25 days of incubation of the leaf explants (Fig. 1a). There was a wide range of variation in percentage of callus induction $(0$ - 95) according to the concentration of hormones (Table 1). About 95\% of leaf discs produced callus on MS medium containing BAP and NAA at
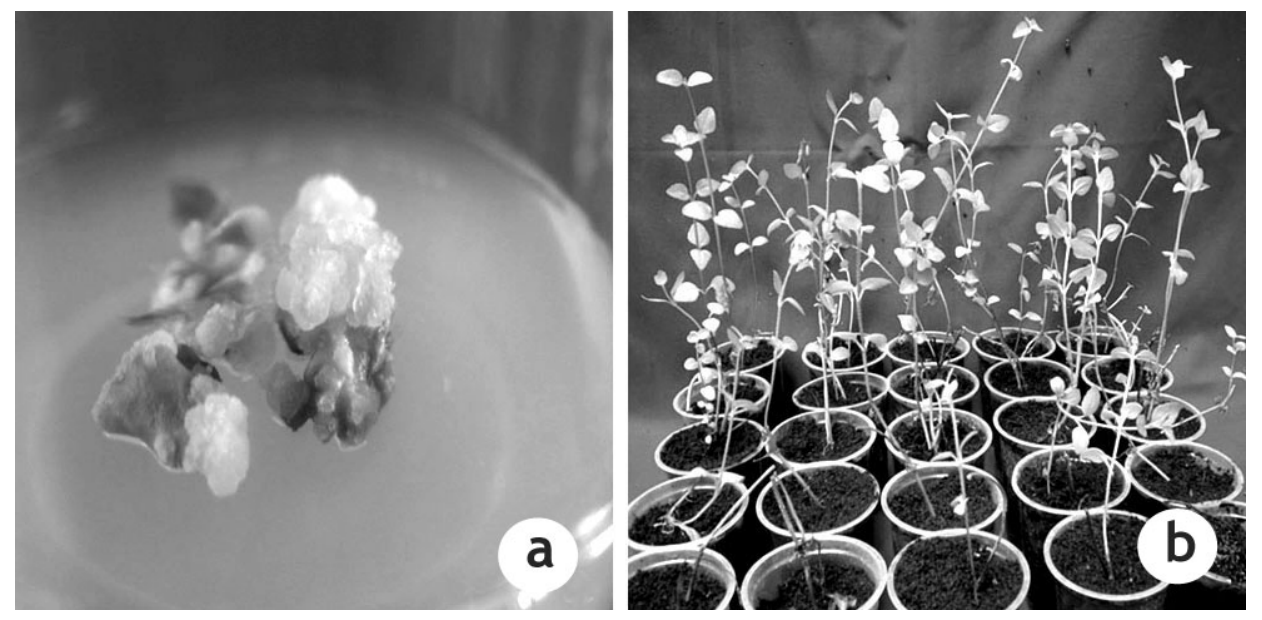

Fig. 1. In vitro regeneration of the species Acmella calva through leaf explant. a. Effective callus formation in basal medium containing BAP and NAA at $3.0 \mathrm{~g} / 1$ and $0.3 \mathrm{mg} / 1$. b. plantlets are growing in pots.

$3 \mathrm{mg} / \mathrm{l}$ and $0.3 \mathrm{mg} / \mathrm{l}$, respectively followed by $85 \%$ callus induction in BAP at 2.5 $\mathrm{mg} / 1$ with NAA at $0.3 \mathrm{mg} / 1$ and $80 \%$ callus production in BAP at $2.0 \mathrm{mg} / 1$ with NAA at $0.3 \mathrm{mg} / \mathrm{l}$. It indicates the importance of BAP in callus formation. Paulsamy et al. (2004) also reported the enhancement of callus producing leaf discs with an increase of BAP concentration as a supplement to the basal medium. It was observed that the shoot formation occurred within four - five weeks after subculturing. It was noted that the low concentrations of BAP alone or BAP with NAA do not promote shoot proliferation (Table 2). The high concentration of BAP and NAA at $3.0 \mathrm{mg} / 1$ and $0.3 \mathrm{mg} / 1$ in basal medium induced a higher amount of (95\%) shoot-forming callus followed by BAP alone at $3.0 \mathrm{mg} / 1(80 \%)$ and BAP at $2.5 \mathrm{mg} / 1$ (70\%). Bringmann and Rischer (2001) have investigated the positive role of the combination of BAP and Kn on the shoot formation of the species, Triphyophyllum peltatum. Furthermore, it was observed that an increase of NAA concentration augmented shoot length up to $8 \mathrm{~cm}$ for Acmella calva (Table 2). Similar pattern of findings has been reported for some species like Petasites hybridus (Wildi et al. 1998), Eucalyptus grandis (Luis et al. 1999) and Hybanthus enneaspermus (Prakash et al. 1999). 
Table 1. Effect of different concentrations of BAP, NAA and $\mathrm{Kn}$ on callus induction from leaf segments of Acmella calva after three weeks of culture.

\begin{tabular}{|c|c|c|c|}
\hline $\begin{array}{l}\text { Treatments }(\mathrm{mg} / 1) \\
\text { (Supplements added to } \\
\text { MS) }\end{array}$ & $\begin{array}{l}\text { Days taken } \\
\text { for callus } \\
\text { initiation }\end{array}$ & $\begin{array}{l}\% \text { of callus } \\
\text { formation }\end{array}$ & $\begin{array}{c}\text { Color of the } \\
\text { callus }\end{array}$ \\
\hline BAP 0.5 & - & - & Green \\
\hline BAP 1.0 & - & - & Green \\
\hline BAP 1.5 & 15 & $30 \pm 2$ & Green \\
\hline BAP 2.0 & 15 & $40 \pm 3$ & Green \\
\hline BAP 2.5 & 15 & $70 \pm 4$ & Green \\
\hline BAP 3.0 & 15 & $75 \pm 4$ & Green \\
\hline BAP 0.5 + NAA 0.3 & 25 & $25 \pm 1$ & Dark green \\
\hline BAP 1.0 + NAA 0.3 & 25 & $45 \pm 3$ & Dark green \\
\hline BAP 1.5 + NAA 0.3 & 25 & $70 \pm 4$ & Dark green \\
\hline BAP $2.0+$ NAA 0.3 & 25 & $80 \pm 5$ & Dark green \\
\hline BAP 2.5 + NAA 0.3 & 25 & $85 \pm 5$ & Dark green \\
\hline BAP 3.0 + NAA 0.3 & 25 & $95 \pm 5$ & Dark green \\
\hline BAP $0.5+$ Kn 0.1 & - & - & Green \\
\hline BAP $1.0+$ Kn 0.1 & - & - & Green \\
\hline BAP 1.5 + Kn 0.2 & 25 & $50 \pm 3$ & Green \\
\hline BAP $2.0+$ Kn 0.2 & 25 & $65 \pm 3$ & Green \\
\hline BAP $3.0+\mathrm{Kn} 0.3$ & 25 & $70 \pm 4$ & Green \\
\hline
\end{tabular}

Table 2. Effect of BAP alone or in combination with NAA and $\mathrm{Kn}$ in MS on organogenesis from leaf derived callus of Acmella calva after 12 weeks of culture.

\begin{tabular}{ccccc}
\hline $\begin{array}{c}\text { Growth regulators } \\
(\mathrm{mg} / \mathrm{l})\end{array}$ & \multicolumn{2}{c}{ Organogenic calli } & $\begin{array}{c}\text { Number of } \\
\text { shoots/callus }\end{array}$ & $\begin{array}{c}\text { Shoot length } \\
(\mathrm{cm})\end{array}$ \\
\cline { 2 - 4 } BAP 0.5 & Root & \% of Shoots & - & - \\
BAP 1.0 & - & - & - & - \\
BAP 1.5 & - & - & - & - \\
BAP 2.0 & - & - & - & - \\
BAP 2.5 & + & $70 \pm 6$ & $18 \pm 3$ & $5 \pm 2$ \\
BAP 3.0 & + & $80 \pm 7$ & $20 \pm 4$ & $5 \pm 2$ \\
BAP 0.5 + NAA 0.3 & - & - & - & - \\
BAP 1.0 + NAA 0.3 & - & - & - & - \\
BAP 1.5 + NAA 0.3 & + & $40 \pm 3$ & $10 \pm 2$ & $6 \pm 3$ \\
BAP 2.0 + NAA 0.3 & - & $40 \pm 3$ & $10 \pm 2$ & $6 \pm 3$ \\
BAP 2.5 + NAA 0.3 & - & $65 \pm 5$ & $14 \pm 3$ & $6 \pm 3$ \\
BAP 3.0 + NAA 0.3 & - & $95 \pm 8$ & $25 \pm 5$ & $6 \pm 3$ \\
BAP 1.5 + NAA 0.5 & - & $40 \pm 3$ & $10 \pm 2$ & $8 \pm 4$ \\
BAP 0.5 + Kn 0.1 & - & - & - & - \\
BAP 1.0 + Kn 0.1 & - & - & - & - \\
BAP 1.5 + Kn 0.2 & + & $50 \pm 4$ & $12 \pm 2$ & $4 \pm 2$ \\
BAP 2.0 + Kn 0.2 & + & $65 \pm 5$ & $14 \pm 3$ & $4 \pm 2$ \\
BAP 3.0 + Kn 0.3 & + & $70 \pm 6$ & $18 \pm 4$ & $4 \pm 2$ \\
\hline
\end{tabular}


Generally, NAA induces rooting during subculturing. However, in the present study, in 95 and $90 \%$ of shoots, roots were initiated, when MS was supplemented with BAP at a concentration of 3 and $2.5 \mathrm{mg} / \mathrm{l}$, respectively (Table 3$)$ and the length of the roots was also higher $(8 \mathrm{~cm})$ when subcultured using BAP at the above concentrations. Mythili and Thomas (1999) also observed better rooting in many cucurbits when subcultured in basal medium supplemented with low level of BAP and other auxins. The hardening experiment showed a high survival rate $(67 \%)$ of plantlets. The best hardening medium was found to be the one containing coir pith and soil in the ratio of $1: 1$. Tissue culture derived plantlets were established in small pots containing soil following hardening (Fig. 1b).

Table 3. Effect of BAP alone and BAP with Kn and NAA in MS on rooting after 30 days of subculture.

\begin{tabular}{lccc}
\hline Growth regulators $(\mathrm{mg} / \mathrm{l})$ & $\begin{array}{c}\text { Number of shoots per } \\
\text { treatment in the } \\
\text { subculture }\end{array}$ & $\begin{array}{c}\text { Shoots } \\
\text { rooted }(\%)\end{array}$ & $\begin{array}{c}\text { Root length } \\
(\mathrm{cm})\end{array}$ \\
\hline BAP 2.5 & $20 \pm 2$ & $90 \pm 7$ & $8 \pm 4$ \\
BAP 3.0 & $30 \pm 3$ & $100 \pm 8$ & $8 \pm 4$ \\
BAP $1.5+$ NAA 0.5 & $10 \pm 1$ & $30 \pm 4$ & $3 \pm 2$ \\
BAP $1.5+$ Kn 0.2 & $12 \pm 1$ & $80 \pm 7$ & $6 \pm 3$ \\
BAP 2.0 + Kn 0.2 & $15 \pm 1$ & $85 \pm 7$ & $6 \pm 3$ \\
BAP 3.0 + Kn 0.3 & $20 \pm 2$ & $85 \pm 7$ & $6 \pm 3$ \\
\hline
\end{tabular}

Acmella calva is of economic interest for its wide range of pharmacological activity and pesticidal property. It is hoped that the protocol reported here to induce multiple shoots may provide a more homogenous source of plants.

The paper reports an efficient and easy-to-use protocol for multiplication of the medicinal herb, Acmella calve through tissue culture. By following this technique, this plant species can be multiplied in bulk and utilized to replenish the degraded shola of the Nilgiris. Once the denuded areas of the Nilgiris is planted with tissue-culture derived medicinal plants on high demand, it will minimize the pressure on the wild population, thus contributing to the conservation of this valuable medicinal plant species.

\section{Acknowledgement}

The authors are grateful to the Ministry of Environment and Forests, Government of India, New Delhi for financial assistance to carryout the work. 


\section{References}

Ansari AH, Mukharya DK and Saxena VK (1988) Analgesic study of n-isobutyl-4, 5decadienamide isolated from the flowers of Spilanthes acmella (Murr). Indian J. Pharm. Sci. 50: 106.

Bringmann G and Rischer H (2001) In vitro propagation of alkaloid producing rare African Liana, Triphyophyllum peltatum. Plant Cell Rep. 20: 591-595.

Mythili JB and Thomas P (1999) Micropropagation of Trichosanthes dioica Roxb. Sci. Hort. 79: 87.

Luis PBC, Adriane CM, Silvica BRCC and Ana Christina MB (1999) Plant regeneration from seedling explants of Eucalyptus grandis $\times$ E. urophylla Plant Cell Tiss. Org. Cult. 56: 17-23.

Paulsamy S, Padmavathy S and Vijayakumar KK (2004) Conservation of an endemic medicinal plant, Berberis tinctoria Lesch. in Nilgiris through micropropagation. Ancient Science of Life 24(1): 22-26.

Paulsamy S (2005) Annual Progress Report of the Project, "Evaluation of conservation strategies for the sustainable utilization of herbaceous bioresources in the sholas of Nilgiris, the Western Ghats", sponsored by the Ministry of Environment and Forests, Govt. of India, New Delhi.

Paulsamy S (2006) "Evaluation of conservation strategies for the sustainable utilization of herbaceous bioresources in the sholas of Nilgiris, the Western Ghats", sponsored by the Ministry of Environment and Forests, Govt. of India, New Delhi.

Pitasawat B, Choochote W, Kanjanapothi D, Panthong A, Jitpakdi A and Chaithong U (1998) Screening for larvicidal activity of ten carminative plants. Southeast Asian J. Trop. Med. Public Health 29: 660.

Prakash E, Khan PS, Sairam Reddy P and Rao KR (1999) Regeneration of plants from seed-derived callus of Hybanthus enneaspermus (L.) Muell., a rare ethnobotanical herb. Plant Cell Rep. 18: 873 - 878.

Purabi Deka and Kalita MC (2005) In vitro clonal propagation and organogenesis in Spilanthes acmella (L.) Murray a herbal pesticidal plant of North-East India. J. Plant Biochemistry \& Biotechnology 14: 69-71.

Ramsewak RS, Erickson AJ and Nair MG (1999) Bioactive N-isobutylamides from the flower buds of Spilanthes acmella. Phytochemistry 51: 729.

Wildi E, Scharrner W and Berger Biiter K (1998) In vitro propagation of Petasites hybridus (Asteraceae) from leaf and petiole explants and from inflorescence buds. Plant Cell Rep. 18: 336-340. 